\title{
EKSPLORASI KEANEKARAGAMAN HERPETOFAUNNA DI KECAMATAN GIRIMULYO KABUPATEN KULON PROGO YOGYAKARTA
}

\author{
Tony Febri Qurniawan, Fuad Uli Addien, Rury Eprilurahman, dan Trijoko \\ Laboratorium Taksonomi Hewan Fakultas Biologi \\ Universitas Gadjah Mada
}

\begin{abstract}
The research was aimed to reveal and document hereptofauna from Girimulyo District Kulon Progo Regency, Daerah Istimewa Yogyakarta Province. This research was done from November-Desember 2008 and JanuaryApril 2009 in four research locations were Girimulyo, Jatimulyo, Giripurwo and Purwosari. The VES (Visual Encounter Survey) method were used and combined with interview method.. A total of 40 species of herpetofauna are indentified and includes in to 13 family. Among 40 species, only one (Michrohyla achatina) is endemic to Java. The commonest herpetofaunas along all site were Eutropis multifasciata and Hylarana chalconota.
\end{abstract}

Keyword: Herpetofauna, species diversity, Girimulyo

\begin{abstract}
ABSTRAK
Penelitian ini bertujuan untuk mengungkap dan mendata keanekaragaman jenis herpetofauna yang ada di Kecamatan Girimulyo. Penelitian dilakukan dari bulan November-Desember 2008, bulan Januari-April 2009 di empat lokasi yaitu Girimulyo, Jatimulyo, Giripurwo dan Purwosari. Metode yang digunakan adalah metode aktif dengan sampling VES (Visual Encounter Survey) dan metode pasif berupa wawancara. Hasil penelitian telah ditemukan 40 jenis herpetofauna yang terdiri dari 13 famili dan hanya 1 jenis yang endemik yaitu Michrohyla achatina. Jenis herpetofauna yang melimpah dan umum ditemukan adalah jenis Eutropis multifasciata dan Hylarana chalconota.
\end{abstract}

Kata kunci: Herpetofauna, Keanekaragaman, Kecamatan Girimulyo 


\section{PENGANTAR}

Indonesia merupakan salah satu negara dengan keanekaragaman hayati yang sangat tinggi. Menurut Russell dalam Tropika (1999), Indonesia termasuk dalam negara Megadiversity. Hal ini disebabkan karena Indonesia mempunyai iklim subtropis sehingga mempunyai banyak hutan hujan tropis yang subur dan membentang luas di daratan Indonesia.

Herpetofauna yang terdiri dari reptilia dan amphibia merupakan salah satu jenis potensi keanekaragaman hayati hewani yang kurang dikenal dan jarang diketahui. Herpetofauna seringkali dianggap mengganggu, menjijikkan, menakutkan bahkan berbahaya sehingga minat terhadap herpetofauna lebih rendah dibandingkan dengan satwa lain seperti mamalia, burung atau ikan. Kurangnya peneliti dan penelitian tentang herpetofauna membuat keberadaan herpetofauna cenderung terabaikan. Keadaan tersebut menyebabkan data mengenai keanekaragaman herpetofauna belum banyak terungkap. Padahal data hasil identifikasi ini sangat penting dalam kegiatan konservasi dan pariwisata

Sebagian besar reptilia dan amphibia dapat dijumpai di hutan-hutan tropis, rawarawa, dan sungai-sungai. Sebaran habitat yang sangat luas ini merupakan faktor utama penentu keanekaragaman jenis. Di Kulon Progo contohnya masih banyak memilki lingkungan yang cocok sebagai habitat herpetofauna, terbukti dengan luasnya areal hutan dan lahan hijau yang dimilikinya. Salah satunya berada di kecamatan Girimulyo. Kondisi lingkungan di kecamatan ini terlihat masih bagus, sehingga memungkinkan hidup beranekaragam herpetofauna.

Herpetofauna sendiri memiliki peranan penting dalam ekosistem, yaitu secara ekologi maupun ekonomi antaralain yaitu peran penting dalam ekosistem dan merupakan bioindikator lingkungan, merupakan predator hama dan serangga yang merugikan manusia (Duelman dan Trueb, 1976), merupakan salah satu hewan eksotik dan komoditas ekspor (Kusrini dan Alford, 2006). Beberapa penelitian yang telah dilakukan dalam jangka waktu beberapa tahun terakhir ini menunjukkan terjadinya penurunan populasi herpetofauna secara global seiring dengan perkembangan iptek. Peristiwa tersebut juga terjadi di Indonesia. Penyebab utama turunnya populasi herpetofauna adalah akibat berkurangnya hutan sebagai habitat asli. Hutan telah terfragmentasi menjadi bagian-bagian kecil yang tersebar membuat populasi spesies juga menjadi populasi yang terpisah-pisah pada bagian kecil habitat tersebut. Hal ini tentu saja menyebabkan herpetofauna di alam sangat rentan terhadap permasalahan genetik dan pada akhirnya terjadi kepunahan secara lokal. Maraknya pembalakan hutan dan kegiatan manusia lainnya merupakan bukti kurangnya perhatian manusia pada keberadaan fauna ini. Eksploitasi berlebih terhadap reptilia dan amphibia baik untuk kepentingan konsumsi maupun hewan peliharaan juga menjadi faktor penyebab penurunan populasi reptilia dan amphibia.

Menurut IUCN (2008), saat ini sepertiga jumlah reptilia dan amphibia di seluruh dunia telah punah, sedangkan dua pertiganya terjadi penurunan populasi secara global dimulai dari tahun 1980-an. Di Indonesia sendiri, penelitian mengenai herpetofauna belum begitu banyak dilakukan. Padahal Indonesia adalah negara terkaya ke-3 di dunia akan jenis herpetofaunanya. Kurangnya survei mengenai keanekaragaman herpetofauna di berbagai wilayah di Indonesia sangat mengkhawatirkan, karena banyak jenis herpetofauna yang hilang sebelum teridentifikasi dan terdata dengan baik. Salah satunya adalah di Kabupaten Kulon Progo. Penelitian mengenai herpetofauna yang hidup di wilayah ini masih sangat minim. Sampai saat ini belum ada publikasi mengenai keanekaragaman jenis dan potensi herpetofauna yang hidup di Kabupaten Kulon Progo, Daerah Istimewa Yogyakarta, 
khususnya di Kecamatan Girimulyo. Oleh karena itu, diadakan penelitian ini untuk mengetahui keanekaragaman jenis dan potensi herpetofauna yang ada di sana. Diharapkan penelitian ini dapat melengkapi database herpetofauna yang ada di Daerah Istimewa Yoyakarta menambah wawasan dalam mengenalkan spesies, karakterisitik habitat, dan potensi kegunaan herpetofauna sehingga diharapkan dapat menjadi motivasi untuk mempelajari dan menjaga kelestarian herpetofauna serta memacu munculnya penelitian-penelitian selanjutnya mengenai herpetofauna di Daerah Istimewa Yogyakarta.

Alat-alat yang digunakan dalam penelitian ini antara lain: Senter dan baterai cadangan, GPS, jam tangan, termometer raksa, $\mathrm{pH}$ meter, meteran gulung dan karton tanda, sweepnet, kompas, caliper, kamera, sarung tangan, kantong plastik, dan botol flakon, karung gandum, alat tulis, dan tabel data. Senter dan baterai cadangan selain sebagai alat penerangan mutlak diperlukan untuk keberhasilan dalam sampling terutama pada malam hari, jam tangan untuk mencatat waktu pengambilan sampel, kamera untuk dokumentasi, GPS untuk mengukur ketinggian dan koordinat lokasi penelitian, termometer raksa untuk mengukur suhu air dan udara, kantong plastik untuk penyimpanan spesimen yang ditangkap, dan alat tulis untuk mencatat data.

Bahan yang digunakan dalam penelitian ini antara lain: klorofom, larutan formalin $4 \%$, dan alkohol 70\%. Larutan formalin 4\%, dan alkohol $70 \%$ untuk mengawetkan sampel yang didapat sedangkan kloroform untuk membius.

Metode yang digunakan dalam penelitian ini adalah metode VES (Visual Encounter Survey) dengan modifikasi transek 200 m (Heyer, 1994). Pengumpulan data keanekaragaman dilakukan pada bulan November-Desember 2007 dan JanuariApril 2008 di Kecamatan Girimulyo dengan 4 lokasi sampling (Gambar 1.) yaitu: Desa Giripurwo (Lokasi I), Desa Girimulyo (Lokasi
II), Desa Jatimulyo (Lokasi III), dan Desa Purwosari (Lokasi IV). Sampling mencakup beberapa area yaitu DAS, non DAS (hutan, pemukiman penduduk, kebun, jalan, sawah). Rute tersebut berupa jalur mengikuti aliran air maupun jalan setapak. Pengamatan dilakukan di sepanjang jalur penjelajahan dan area sekitarnya. Pengamatan dilakukan pada siang hari (jam 07.00 - 11.30) dan malam hari (jam 19.00 - 22.30) untuk mendapatkan data jenis nokturnal dan diurnal.

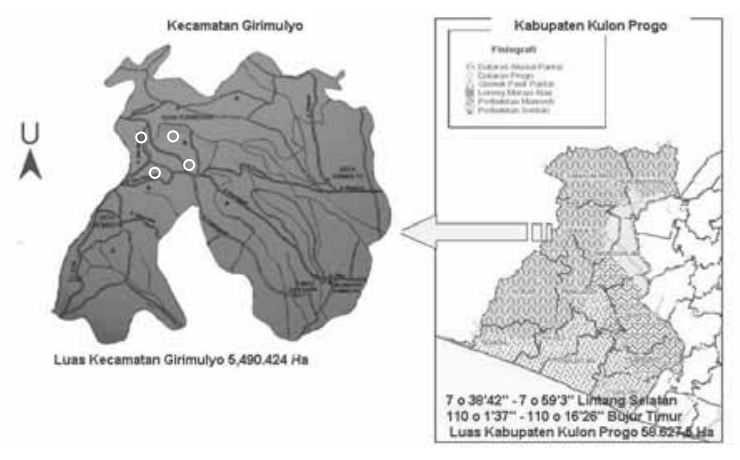

Gambar 1.

Peta lokasi penelitian ( lokasi sampling ditandai lingkaran )

Masing-masing lokasi penelitian Dilakukan pendataan meliputi: waktu penjumpaan, jenis kelamin, dan aktivitas ketika dijumpai. Individu yang dijumpai diidentifikasi langsung di lokasi dengan metode taksomorfologi. Selain itu, parameter lingkungan di tempat sampling juga diambil, meliputi: suhu dan $\mathrm{pH}$ air serta Suhu udara sebelum maupun sesudah sampling. Dilakukan juga pencaria informasi mengenai potensi herpetofauna dengan melakukan wawancara langsung dengan beberapa warga.

Spesies yang dijumpai diidentifikasi langsung di lokasi dengan metode taksomorfologi, yaitu proses klasifikasi berdasarkan data morfologidan deskripsiamfibi yang diperoleh. Identifikasi dan deskripsi jenis anuran menggunakan De Roij (1915), De Rooij (1917), Kurniati (2003), Das (2004), Mattison (1992), Berry (1975), dan Iskandar (1998) 
Hasil data yang didapat dianalisis menggunakan indeks diversitas ShanonWeiner, indeks kemerataan Simpson, indeks kekayaan jenis Margalef, indeks Similiaritas Jaccard dan indeks Canberra yang formula sebagai berikut :

Indeks diversitas dari Shannon Weaver $\mathrm{H}^{\prime}=-\sum_{i-1}^{\mathrm{s}} p i \operatorname{loge} p i$

dengan :

$\mathrm{H}^{\prime}$ : Indeks keanekaragaman ShannonWiener

$n_{\mathrm{i}}$ : Jumlah individu jenis ke-i

$\mathrm{N}$ : Jumlah individu seluruh jenis

Menurut Brower \& Zarr (1997) indeks diversitas dikatakan tinggi jika nilainya lebih dari 2,0 dan sedang jika nilainya antara 1,5-2,0 sedangkan rendah jika nilainya antara 1,0-1,5 dan sangat rendah jika kurang dari 1,0.

Untuk mengetahui derajat kemerataan jenis pada lokasi penelitian digunakan indeks sebagai berikut.

$\mathrm{E}=\frac{\mathrm{H}^{\prime}}{\mathrm{Ln} S}$

dengan :

E : Indeks kemerataan jenis

$\mathrm{H}^{\prime}$ : Indeks keanekaragaman ShannonWiener

S : Jumlah jenis yang ditemukan

Indeks kesamaan jenis digunakan untuk mengetahui kesamaan antar lokasi pengamatan berdasarkan jenis herpetofauna yang ditemukan dengan menggunakan Indeks Similaritas Komunitas Jaccard.

$\mathrm{IS}_{\mathrm{j}}=\frac{\mathrm{C}}{\mathrm{S}_{1}+\mathrm{S}_{2}+\mathrm{C}}$

dengan :

IS: Indeks Similaritas Jaccard

C: Jumlah jenis terdapat di kedua lokasi

$S_{1}$ : Jumlah jenis terdapat di lokasi A saja

$\mathrm{S}_{2}$ : Jumlah jenis terdapata di lokasi B saja
Kekayaan jenis Indeks Margalef

$$
\mathrm{R}_{1}=\frac{\mathrm{S}-1}{\operatorname{In}(\mathrm{n})}
$$

Sedangkan untuk membandingkan kesamaan habitat berdasarkan nilai parameter fisika dapat dianalisis dengan indeks Canberra.

$$
\mathrm{Sc}=\left\{1-1 / \mathrm{n} \Sigma\left|\frac{\mathrm{yi}_{1}-\mathrm{yi}_{2}}{\mathrm{yi} i_{1}+\mathrm{yi}}\right|\right\} \times 100 \%
$$

dengan :

Sc $=$ Indeks Canberra (\%)

$Y i_{1}=$ parameter $i$ stasiun 1

$Y i_{2}=$ parameter $i$ stasiun 2

$n=$ jumlah parameter

\section{PEMBAHASAN}

Secara umum lokasi penelitian merupakan wilayah perbukitan menoreh yang masih banyak terdapat hutan, sungai, dan sumber mata air bawah tanah. Lokasi satu dengan lokasi lainnya ternyata memiliki beberapa kesamaan dan perbedaan karakter habitat. Sehingga komposisi jenis herpetofauna yang hidup di masing-masing lokasi juga berbeda. Untuk lebih rincinya, pada Tabel 1 berikut ini menyajikan bagaimana kondisi dan beberapa karakter habitat yang dimiliki di masingmasing lokasi pengamatan.

Tabel 1.

Faktor lingkungan masing-masing lokasi pengamatan

(sumber : Bappeda DIY dan Bakosurtanal, 2002)

\begin{tabular}{lllll}
\hline \multicolumn{1}{c}{$\begin{array}{c}\text { Faktor } \\
\text { lingkungan }\end{array}$} & \multicolumn{4}{c}{ Desa } \\
\cline { 2 - 5 } & Giripurwo & Girimulyo & Jatimulyo & Purwosari \\
\hline $\begin{array}{l}\text { Kemiringan } \\
(\%)\end{array}$ & $15-40$ & $15-40$ & $15-40$ & $15-40$ \\
$\begin{array}{l}\text { Elevasi (m) } \\
\text { Curah hujan } \\
\text { (mm/tahun) }\end{array}$ & $26-1000$ & $100-1000$ & $300-1000$ & $100-1000$ \\
$\begin{array}{l}\text { Tipe tanah } \\
\text { fisiografi }\end{array}$ & Grimusol & Latosol & Latosol & Latosol \\
$\begin{array}{l}\text { Air Bawah } \\
\text { Tanah }\end{array}$ & Karst & Vulkanik & Vulkanik & Vulkanik \\
$\begin{array}{l}\text { Bentang } \\
\text { Alam }\end{array}$ & Hutan & tua & tua & tua \\
$\begin{array}{l}\text { Polusi } \\
\text { Industri }\end{array}$ & Tidak ada & Tidak ada & Tidak ada & Tidak ada \\
Kelembaban & 80 & 82 & 83 & 82 \\
\hline
\end{tabular}


Tabel 1 menunjukkan antara lokasi yang satu dengan yang lain memiliki kesamaan dalam hal kemiringan, keadaan fisiografik, dan bentang alam. Sedangkan perbedaannya terletak pada elevasi, curah hujan per tahun, tipe tanah, dan kelembaban. Semua faktor tersebut memilki pengaruh besar terhadap kehidupan herpetofauna di sana, terutama bentang alam, curah hujan, kelembaban, dan elevasi. Bentang alam yang ada berhubungan erat dengan kelangsungan hidup herpetofauna dalam memperoleh nutrisi. Sedangkan curah hujan, kelembaban, dan elevasi memiliki peran dalam menciptakan makrohabitat dengan suhu tertentu yang ideal untuk tempat tinggal serta berkembang biak herpetofauna disana.

Data yang didapatkan dari hasil pengamatan selama 6 kali sampling, enunjukkan nilai rerata parameter fisik (suhu udara, suhua air dan $\mathrm{pH}$ ) di masing-masing lokasi pengamatan adalah sebagai berikut:

Tabel 2.

Data rerata parameter fisik

\begin{tabular}{llllll}
\hline \multirow{2}{*}{ No } & \multirow{2}{*}{ Parameter } & \multicolumn{4}{c}{ Lokasi } \\
\cline { 3 - 6 } & & \multicolumn{1}{c}{ I } & II & III & IV \\
\hline 1 & Suhu Udara $\left({ }^{\circ} \mathrm{C}\right)$ & 22.42 & 22.1 & 22.41 & 22.16 \\
2 & Suhu Air $\left({ }^{\circ} \mathrm{C}\right)$ & 21.51 & 21.44 & 21.08 & 21.27 \\
3 & $\mathrm{pH}$ & 7 & 7 & 7.01 & 7.08 \\
\hline
\end{tabular}

Hasil pengukuran parameter fisik di atas, lalu dianalisis seberapa besarkah nilai kesamaan kondisi fisik antara lokasi satu dengan loaksi lain menggunakan indeks kesamaan Canberra. Hasil analisis disajikan pada tabel 3. di bawah ini:

Tabel 3.

Matriks kemiripan antar lokasi berdasar parameter fisik

\begin{tabular}{|c|c|crr|}
\hline IS & In & II & II & IV \\
\hline I & & 38.46 & 36.68 & 43.48 \\
II & & & 60.53 & 47.06 \\
III & & & & 53.85 \\
IV & & & & \\
\end{tabular}

Nilai kemiripan lokasi digunakan untuk mengetahui adanya kesamaan dan membandingkan kesamaan habitat pada setiap lokasi pengamatan. Pada Tabel 3. lokasi II (Girimulyo) dengan lokasi III (Jatimulyo) memiliki nilai kesamaan habitat sebesar $60,53 \%$. Hal ini berarti lokasi II dengan III memiliki kesamaan habitat yang relatif mirip berdasarkan parameter fisik. Namun nilai kesamaan yang diperoleh dalam penelitian ini kemungkinan memiliki bias yang disebabkan oleh faktor kimia, faktor geografis dan beberapa faktor fisik lainnya yang tidak ikut diukur sebagai parameter. Semua faktorfaktor tersebut akan berpengaruh terhadap komposisi dan penyebaran herpetofauna di masing-masing lokasi.

Berdasarkan hasil penelitian, telah ditemukan 40 jenis herpetofauna yang termasuk ke dalam 7 famili anggota kelas reptiliaia dan 6 famili anggota kelas amphibiaaa. Total dari 40 jenis herpetofauna yang ditemukan, 15 jenis diantaranya anggota ordo anura, 15 jenis anggota sub ordo lasertilia dan 10 jenis dari anggota sub ordo serpentes. Sedangkan berdasarkan perhitungan persentase jumlah individu tiap jenis, maka dapat diketahui jenis herpetofauna yang paling banyak ditemukan di Girimulyo adalah kadal kebun (Eutropis multifasciata) sebesar $70 \%$. Lalu 4 jenis herpetofauna lainnya yang banyak ditemukan setelah $E$. multifasciata adalah katak kongkang kolam (Hydrophylax chalconotus) sebesar $65 \%$, kodok bangkong sungai (Phrynoidis aspera) sebesar $62 \%$, katak serasah (Leptobrachium hasseltii) sebesar $56 \%$ dan kodok bangkong darat (Duttaphrynus melanostictus) sebesar 49 \%. Hal ini mungkin disebabkan karena $E$. multifasciata dan beberapa jenis dari anggota ordo anura memiliki kepadatan yang tinggi dan persebarannya yang luas serta dapat hidup di berbagai jenis habitat selama di habitat tersebut memiliki sumber air. Apalagi Eutropis multifasciata dan Duttaphrynus melanostictus sendiri telah dikenal sebagai jenis herpetofauna yang kosmopolitan. Sedangkan 
jenis herpetofauna yang paling sedikit dijumpai hampir semuanya dari anggota sub ordo serpentes dan beberapa dari anggota sub ordo lasertilia yaitu hanya sebesar $1 \%$. Jenis-jenis tersebut antara lain yakni ular berkepala dua (Calamaria linneai), ular bajing (Gonyosoma oxichepalum), ular sanca kembang (Pthyton reticulatus), ular weling (Bungarus candidus), kadal rumput (Takydromus sexlineatus), kadal serasah bergaris (Eutropis rugifera), dan londok moncong (Pseudocalotes tympanistigra). Kemungkinan jenis reptilia tersebut memiliki kepadatan yang rendah dan pandai bersembunyi sehingga sulit untuk dijumpai.

Berdasarkan komposisi jenis yang ditemukan, 17 jenis herpetofauna ditemukan di Giripurwo, sedangkan di Girimulyo ditemukan 37 jenis, lalu 24 jenis ditemukan di Jatimulyo, dan 16 jenis di Purwosari. Dari 4 lokasi sampling, masing-masing memiliki jenis kumulatif yang berbeda. Jenis herpetofauna yang ditemukan masingmasing lokasipun ada beberapa jenis yang sama dan ada beberapa juga jenis yang spesifik hanya ditemukan dilokasi tertentu. Bungarus candidus dan Takydromus sexlineatus selama pengamatan hanya ditemukan di Giripurwo, lalu Eutropis rugifera yang hanya ditemukan di Jatimulyo, jenis lain seperti katak pohon hijau (Rhacophorus reindwardtii), cicak terbang (Ptycozoon kuhlii), londok moncong (Pseudocalotes tympanistriga), ular kepala dua (Calamaria linneai), ular truno bamban (Cryptelytrops albolabris), ular bajing (Gonyosoma ocichepalum), ular air (Xenochropis trianguligerus) dan ular pucuk (Ahaetulla prasina) juga hanya ditemukan dilokasi Girimulyo saja. Jenis kumulatif dan jenis spesifik paling banyak ditemukan di lokasi Girimulyo. Hal ini mungkin disebabkan lokasi di Girimulyo kondisinya masih bagus dan belum begitu terganggu aktivitas manusia, sehingga keseimbangan ekosistemnya masih terjaga.
Data hasil perhitungan indeks diversitas tersaji pada gambar 2. sebagai berikut:

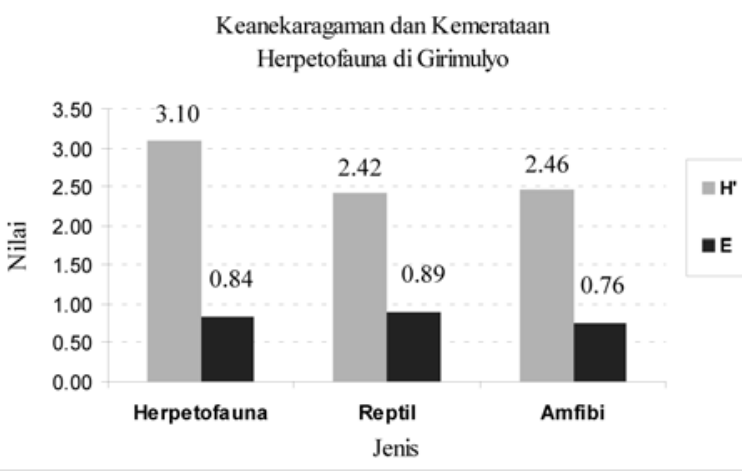

Gambar 2.

Hasil perhitungan indeks diversitas

Berdasarkan Gambar 2 dan Tabel 4, diketahui indeks diversitas herpetofauna di Girimulyo memiliki kisaran indeks diversitas dari 2,22 hingga 2,97. Indeks diversitas total pada semua lokasi adalah 3,10 dimana tergolong tinggi. Dari gambar 10. diketahui bahwa keanekaragaman amphibiaa lebih tinggi $(2,46)$ daripada reptilia $(2,42)$. Dari Tabel 5. dominasi kumulatif dipegang oleh lokasi II yaitu Girimulyo $(0,054)$, sedangkan kedua, lokasi III yaitu Jatimulyo dan yang ketiga, lokasi I yaitu Giripurwo.

Tabel 4.

Indeks diversitas herpetofauna Girimulyo

\begin{tabular}{|c|c|c|c|c|}
\hline Indikasi & I & II & III & IV \\
\hline \multicolumn{5}{|l|}{ Kekayaan } \\
\hline $\mathrm{N}$ & 81 & 231 & 263 & 95 \\
\hline R1 & 3.64 & 6.61 & 2.87 & 3.3 \\
\hline \multicolumn{5}{|c|}{ Keanekaragaman } \\
\hline $\mathrm{S}$ & 17 & 37 & 24 & 7 \\
\hline $\mathrm{H}^{\prime}$ & 2.46 & 2.97 & 2.22 & 2.5 \\
\hline $\mathrm{E}$ & 0.867 & 0.822 & 0.875 & 0.9 \\
\hline
\end{tabular}

Berdasarakan Tabel 4, dapat diketahui bahwa indeks tertinggi terdapat pada lokasi ke II (Girimulyo), yaitu 2,95 sedangkan indeks terendah pada lokasi III (Purwosari), yaitu 2,22. Pada Tabel 4 juga menunjukkan bahwa indeks diversitas lokasi II (Girimulyo) yang tinggi itu bisa jadi diperoleh dari komunitas dengan kekayaan herpetofauna 
yang tinggi dan kemerataan yang relatif tinggi. Hal ini dibuktikan akumulasi penambahan spesies tiap penambahan pengamatan di lokasi II terus naik (Gambar 8). Darmawan (2006) menyatakan bahwa apabila keanekaragaman dalam satu komunitas tinggi maka keseimbangan antar jenis juga tinggi, tetapi tidak berlaku sebaliknya. Pada dasarnya keanekagaraman herpetofauna di habitat yang tidak terganggu lebih tinggi dibandingkan dengan habitat yang terganggu. Pada habitat yang tidak terganggu umumnya memiliki keseimbangan yang tinggi, karena memungkinkan adanya ruang ekologi untuk saling memberi dan menerima.

Tabel 5.

Hasil perhitungan nilai kesamaan jenis

\begin{tabular}{|c|c|ccc|}
\hline IS $_{\text {Jaccard }}$ & I & II & III & IV \\
\hline I & & 99.78 & 99.72 & 99.57 \\
II & & & 99.6 & 99.72 \\
III & & & & 99.5 \\
IV & & & & \\
\hline
\end{tabular}

Berdasarkan perbedaan jenis herpetofauna yang ditemukan di masing-masing lokasi, maka antara lokasi satu dengan lokasi yang lain dapat kita hitung berapa besarkah kesamaan jenis herpetofauna yang ada pada masing-masing lokasi. Hal ini berguna untuk mengetahui adakah perbedaan persebaran herpetofauna di masing-masing lokasi, jika semakin tinggi kesamaan jenis herpetofauna yang ada, maka kemungkinan besar habitatnya memiliki kondisi yang sama. Namun tentu saja hal ini tidak dapat menjadi patokan dasar. Dari Tabel 5 di atas, nilai indeks kesamaan jenis yang diperoleh dalam penelitian ini berkisar antara 99,5 sampai 99,78. Selisihnya begitu kecil, ini menandakan komposisi jenis herpetofauna yang ditemukan masing-masing lokasi umumnya sama. Besarnya kesamaan jenis menandakan kondisi dan karakterisitik habitat masing-masing lokasi pengamatan memiliki kesamaan.

\section{SIMPULAN}

Kecamatan Girimulyo memiliki 40 jenis herpetofauna yang terdiri dari 7 famili anggota kelas reptilia (4 jenis Agamidae, 7 jenis Gekkonidae, 4 jenis Scincidae, 7 jenis Colubridae, 1 jenis Viperidae, 1 jenis Elapidae,dan 1 jenis Pythonidae) dan 6 famili anggota kelas amphibia (3 jenis Bufonidae, 2 jenis Microhylidae, 2 jenis Ranidae, 2 jenis Rhacophoridae, 5 jenis Dicroglossidae, dan 1 jenis Megophrydae). Indeks diversitas herpetofauna secara keseluruhan indeks diversitas tergolong tinggi yaitu sebesar 3,10 dengan rincian pada lokasi I 2,46; loaksi II 2,97; lokasi III 2,22 dan lokasi IV 2,5.

\section{DAFTAR PUSTAKA}

Bakosurtanal, 2002, Peta Wates Kabupaten Kulonprogo, Pusat Penelitian Informasi Kebumian, Bakosurtnal, Yogyakarta.

Bappeda, 2002, Atlas Kabupaten Kulonprogo, Development data DIY Province.

Berry, P. Y, 1975, The Amphibian Fauna of Peninsular Malaya, Tropical Press.

Budden, D.W, 2000, The Reptiles of Pohnpei, federated States of Micronesia, Micronesia 32 (2), 155-180, Dalam: Kurniati 2003, Amfibia dan Reptilia Cagar Alam Gunung Supiori, Biak-Numfor: Daerah Korido dan Sekitarnya, Berita Biologi vo.6 no. 5, Agusuts 2003, hlm: 691-697.

Brower JE and Jh Zarr, 1997, Field and Laboratory For General Ecology, W.M.C Brown Company Publishing, Portugue, IOWA.

Darmawan, M. P, 2006, Keanekaragaman Jenis Burung Pada Beberapa Tipe Habitat Di Hutan Lindung Gunung Lumut Kalimantan Timur, Skripsi. Bogor: Institut Pertenian Bogor, hlm: 130. 


\section{TONY FEBRI QURNIAWAN, FUAD ULI ADDIEN, RURY EPRILURAHMAN, DAN TRIJOKO EKSPLORASI KEANEKARAGAMAN HERPETOFAUNNA DI KECAMATAN ...}

Das, Indraneil, 2004, Lizards of Borneo: A Pocket Guide, Natural History Publication (Borneo) Sdn. Bhd. Kota Kinabalu.

De Roij, N.1915. The reptiles of the IndoAustralian Archipelago I. Lacertilia, Chelonia, Emydosauria.EJ Brill, Leiden.

De Roij, N.1917. The reptiles of the IndoAustralian Archipelago II. Ophidia. EJ Brill, Leiden

Duellman, W.E and L. Trueb.,1976, Biology of Amphibians, McGraw-hill book Company, New York. P: 1, 197 - 225

Heyer, W.R., M.A. Donnelly, R.W. McDiarmid, L.C. Hayek and M.S. Foster, 1994, Measuring And Monitoring Biological Diversity: Standard Methods For Amphibians. Smithsonian Institution Press, Washington, hlm: 364.

Hoesel, J.K.P. van. 1959, Ophidia Javanica, Pertjetakan Archipel, Bogor.

Iskandar, D.T, 1998, Amphibia of Java and Bali, Research and development Center for Biology-LIPI, Bogor
IUCN, Conservation International, and Nature Serve, 2008, Red List Category [online] 2008, Avalaible from: URL: http:/ / www.globalamphibians.org. accessed February 25, 2008.

Kurniati, H, 2003, Amphibian \& Reptiliaes of Gunung Halimun National Park West Java, Indonesia (Frog, Lizard and Snakes): An Illustrated Guide Book, Research Center for Biology (LIPI) and Nagao Natural Environment Foundation (NEF), Cibinong.

Kusrini, D.M., Alford,A.R, 2006, Indonesia's Export of Frog's Leg's. Dalam: Traffic Bulletin vol. 21 July 2006, Thanet Press Ltd,Union Crescent, Margate, Kent, UK,hlm: 17-28.

Mattison, C, 1992, Lizards of The World, Blandford. London.

Russell, A.M, 1999, Megadiversity dalam: Buletin Tropika Indonesia Vol III Keanekaragaman Hayati Indonesia, Sanggupkah Mengatasi Krisis?, Concervation Internasional Indonesia Program Pelestarian Hayati Indonesia, Pejaten Barat Pasar Minggu, Jakarta, hlm: 1-8. 